\title{
Estimation of Photosynthesis Loss Due to Greenhouse Superstructures and Shade Nets: A Case Study with Paprika and Tomato Canopies
}

Koichi Nomura, Masahiko Saito, Ikunao Tada, Tadashige Iwao, and Tomihiro Yamazaki

IoP Collaborative Creation Center, Kochi University, 200, Otsu, Monobe, Nankoku City, Kochi 783-8502, Japan

Nobuyuki Kira, Yasuyo Nishimura, and Makito Mori

Faculty of Agriculture and Marine Sciences, Kochi University, 200, Otsu, Monobe, Nankoku City, Kochi 783-8502, Japan

\section{Esteban Baeza}

Future Farms Solutions, Avenida de la Innovación 15, 04131 Almería, Spain

\section{Masaharu Kitano \\ IoP Collaborative Creation Center, Kochi University, 200, Otsu, Monobe, Nankoku City, Kochi 783-8502, Japan}

Additional index words. canopy photosynthesis, diffused plastic film, ethylene tetrafluoroethylene, ETFE, greenhouse temperature, light photosynthesis curve

\begin{abstract}
In horticultural greenhouses, the photosynthetic photon flux density $(I)$ is inevitably lower than that outside because of interference from greenhouse superstructures (e.g., reflection and absorption of radiation by greenhouse coverings and superstructures). In addition, during hot seasons in many regions, $I$ can be lowered by shade nets installed to reduce excessive radiation. These reductions in $I$ can cause a decrease in the canopy photosynthetic rate $\left(A_{\mathrm{c}}\right)$, potentially leading to crop yield losses. This study investigated to what extent $A_{\mathrm{c}}$ is reduced inside a modern greenhouse and under a shade net in comparison with that outside. A simple $A_{\mathrm{c}}$ model (i.e., canopy-scale photosynthesis-light curves) was parameterized based on the measurements of $A_{\mathrm{c}}$ and $I$ for paprika and tomato canopies using the open-chamber method. In addition, based on the measurements of $I$, linear regression models were derived that related outside $I$ $\left(I_{\text {out }}\right)$ with $I$ inside arch-roofed, single-span greenhouses [enveloped with a diffuse ethylene tetrafluoroethylene (ETFE) film; $I_{\text {in }}$ and $I$ under shade nets (composed of aluminum and polyester strips; $\left.I_{\mathrm{sh}}\right)$. An $A_{\mathrm{c}}$ simulation using these models indicated that on a typical sunny summer day in Japan, $A_{\mathrm{c}}$ inside the greenhouses and under the shade nets $\left(A_{\mathrm{c}, \text { in }}\right.$ and $A_{\mathrm{c}, \mathrm{sh}}$, respectively) corresponded to $91 \%$ and $52 \%$ of $A_{\mathrm{c}}$ outside $\left(A_{\mathrm{c}, \mathrm{out}}\right)$ for the paprika canopy (for the tomato canopy, $A_{\mathrm{c}, \text { in }}$ and $A_{\mathrm{c}, \mathrm{sh}}$ corresponded to $90 \%$ and $48 \%$ of $A_{\mathrm{c}, \text { out }}$, respectively). The simulated $A_{\mathrm{c}}$ loss was more serious on a cloudy day because of the linear $A_{\mathrm{c}}-I$ response under low $I$ conditions $\left(A_{\mathrm{c}, \text { in }} / A_{\mathrm{c}, \text { out }}\right.$ and $\left.A_{\mathrm{c}, \mathrm{sh}}\right)$ $A_{\mathrm{c}, \text { out }}$ were $69 \%$ and $13 \%$, respectively, for the paprika canopy). The loss of $A_{\mathrm{c}, \mathrm{sh}}$ may be alleviated by limiting the shading period to only midday hours.
\end{abstract}

In modern horticultural crop production, wherever root-zone environments are optimally managed, canopy photosynthesis

Received for publication 10 Nov. 2021. Accepted for publication 3 Jan. 2022.

Published online 8 February 2022.

This study was supported by a Cabinet Office grantin-aid, the Advanced Next-Generation Greenhouse Horticulture by IoP (Internet of Plants), Japan, and JSPS KAKENHI Grant Number JP21K14946.

K.N. is the corresponding author. E-mail: jm-koichi. nomura@kochi-u.ac.jp.

This is an open access article distributed under the CC BY-NC-ND license (https://creativecommons. org/licenses/by-nc-nd/4.0/). the first step in the photosynthetic reaction. However, in a greenhouse, incoming $P A R$ can be quite different from the $P A R$ outside, depending on the type of greenhouse cover (Baeza et al., 2020; Giacomelli and Roberts, 1993; Pearson et al., 1995). Depending on the transmissivity of the cover material, the photosynthetic photon flux density (PPFD; $I$ ) in the greenhouse can become considerably lower than that outside. In addition, some cover materials have diffusing properties, making incoming radiation more uniform (Hemming et al., 2008) and improving $A_{\mathrm{c}}$ ( $\mathrm{Li}$ et al., 2014). Furthermore, greenhouse superstructures (e.g., ridges, trusses, and beams) can block and reduce the incoming PAR (Giacomelli and Roberts, 1993; von Elsner et al., 2000). These complicating factors and their interactions determine $I$ inside a greenhouse.

In temperate and subtropical regions (e.g., many parts of Japan), incoming radiation can bring excessive energy into a greenhouse from late spring to early autumn. This radiation not only warms up the greenhouse but also reaches human workers, raising the apparent temperature (i.e., the temperature equivalent perceived by humans) to an unbearable point. To reduce such excessive radiation, modern greenhouses are often equipped with movable shade nets below the roofs (Castellano et al., 2008). These shade nets can be extended to cover the entire greenhouse area and create a shade, decreasing both the actual and apparent temperatures. Such shade treatment is expected to become more important in greenhouse horticulture, as global warming is rapidly progressing (Bisbis et al., 2019). An obvious drawback of these shade nets is the reduction in $P A R$ and $A_{\mathrm{c}}$ (Hernández et al., 2015, 2019; Kitta and Katsoulas, 2020; López-Marín et al., 2012; Masabni et al., 2016). Because $A_{\mathrm{c}}$ is closely related to crop yield, inappropriate use of shade nets may result in reduced crop yield. In practice, however, shade nets are often used without considering their effects on $A_{\mathrm{c}}$, and quantitative information on the loss of $A_{\mathrm{c}}$ due to shade-net operations is lacking.

The purpose of the present study was to assess to what extent the $A_{\mathrm{c}}$ of horticultural fruit vegetables is reduced due to greenhouse superstructures and shade nets in comparison with that outside. To achieve this objective, we first investigated the $A_{\mathrm{c}}$ of paprika (Capsicum annuum L.) and tomato (Solanum lycopersicum L.) canopies with the commonly used open-chamber method and then obtained model parameters for a simple empirical canopy photosynthesis model representing the response of $A_{\mathrm{c}}$ to $I$. Next, we measured $I$ outside and inside greenhouses and under shade nets ( $I_{\text {out }}, I_{\text {in }}$ and $I_{\text {sh }}$, respectively) and derived regression models that related $I_{\text {out }}$ with $I_{\text {in }}$ and $I_{\mathrm{sh}}$. The effects of shade nets on greenhouse air temperature were also evaluated. Finally, using the empirical model of the relationship between $A_{\mathrm{c}}$ and $I$, we evaluated the loss of $A_{\mathrm{c}}$ due to the greenhouse superstructures and shade nets. 


\section{Materials and Methods}

\section{Greenhouse and experimental setup}

All experiments were conducted in the Nankoku Field located at Monobe Campus, Kochi University $\left(33^{\circ} 33^{\prime} 4^{\prime \prime} \mathrm{N}, 133^{\circ} 40^{\prime} 37^{\prime \prime} \mathrm{E}\right)$. Two identical, arch-roofed single-span greenhouses were used (Fig. 1). Each of the two greenhouses was $50 \mathrm{~m}$ long, $9 \mathrm{~m}$ wide, and $5.2 \mathrm{~m}$ high (at the center) and north-south oriented (i.e., the ridges of the greenhouses ran north-south). These two greenhouses were constructed side by side and were only 4.25 $\mathrm{m}$ away from each other. These greenhouses were enveloped with a diffuse ETFE film (F-CLEAN Diffused; AGC Green-Tech Co., Ltd., Tokyo, Japan). This covering material has high transmissivity for $P A R$ with haze (i.e., a light-diffusing property) to improve canopy photosynthesis (hemispherical transmission $=0.81$; Hemming et al., 2008). The covering material was less than 2 years old at the time of the experiment. The two greenhouses were equipped with movable shade nets (TEMPA 6562 D; Ludvig Svensson,
Kinna, Sweden) on the inside, $\approx 3 \mathrm{~m}$ above the ground. The shade nets are composed of aluminum and polyester strips $(4 \mathrm{~mm}$ wide each) woven in a stripe pattern at a ratio of 5:3 (aluminum: polyester). According to the manufacturer's specifications, the transmissivities for direct and diffuse light are $35 \%$ and $32 \%$, respectively. These shade nets can be extended/folded similarly to curtains with motors and can cover the entire ground area of each greenhouse. For ventilation and temperature control, each greenhouse was equipped with motor-operated top and side windows along the north-south direction; the top windows were $0.85 \mathrm{~m}$ wide and equipped on both sides of the roof ridge, and the side windows were $2.5 \mathrm{~m}$ high and equipped on the east and west sides of each greenhouse. During this study, the top and side windows were all fully open, and the window openings were covered with insect screens with the mesh size of $0.4 \mathrm{~mm}$. The air inside each greenhouse was mixed using four $36-\mathrm{cm}$ diameter electric fans (AB363NA; Fulta Electric Machinery Co., Ltd, Aichi, Japan) installed at the beams. These fans were switched on and off at 10-min intervals.

\section{Plant materials and cultivation conditions}

Paprika and tomato canopies were cultivated hydroponically in each of the two greenhouses. In one greenhouse (Greenhouse 1), tomato plants $(S$. lycopersicum L., variety 'Momotaro Peace') were cultivated using the nutrient film technique (NFT) with a planting density of 1.9 plants $/ \mathrm{m}^{2}(180 \mathrm{~cm}$ between rows and $20 \mathrm{~cm}$ between plants within a row). These tomato plants were seeded on 28 July 2020 , and transplanted to NFT panels on 6 Aug. 2020. The plants were pruned to a single shoot and led with support strings tied to one of two parallel wires $2.0 \mathrm{~m}$ above the ground. Once the plants reached the wire height, the plants were leaned forward and lowered by $\approx 50$ $\mathrm{cm}$ by releasing the support strings from the wires. These actions of leaning and lowering move plants forward along the wire. Once a plant reached the edge of the row, the plant
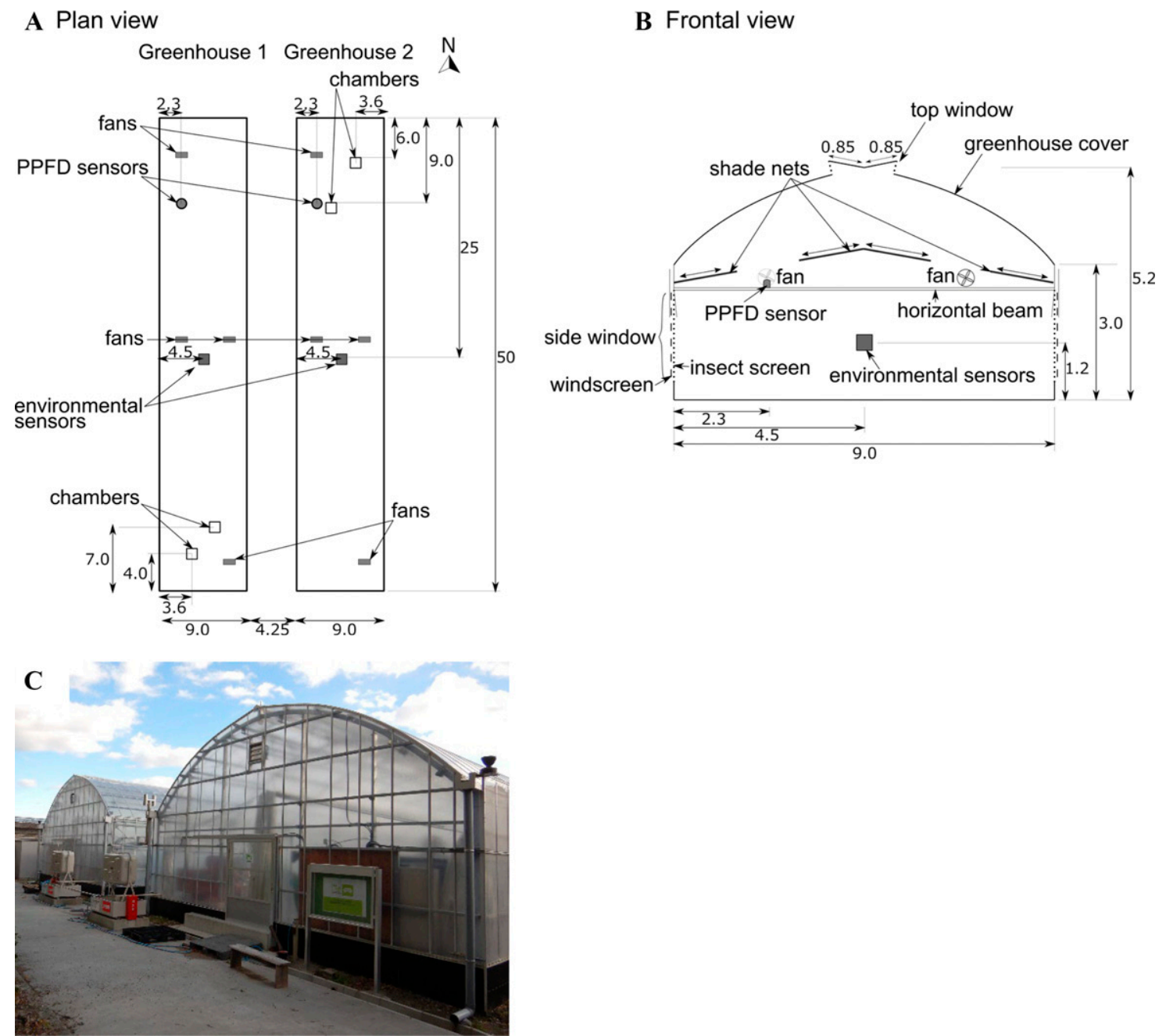

Fig. 1. Experimental greenhouses. (A) Plan view of the two experimental greenhouses. (B) Frontal view of one of the greenhouses. The arrows over the shade nets indicate that these shade nets can be extended (closed) or folded (opened). The dotted lines at the side and top windows represent insect screens with a mesh size of $0.4 \mathrm{~mm}$, whereas the broken lines at the side windows represent a windscreen with a mesh size of $6 \mathrm{~mm}$. All lengths in the figures are in meters. (C) Photograph of the experimental greenhouses taken from the northwest side. 
was turned back using the other wire. The leaves were pruned once all the fruits on the nearest upper truss were harvested. The tomato plants were supplied with the OAT SA nutrient solution (OAT Agrio Co., Ltd., Tokyo, Japan) with an electrical conductivity (EC) of $2.2 \mathrm{dS} \cdot \mathrm{m}^{-1}$. The nutrient supply was switched on and off every 5 min to provide the plant roots with sufficient oxygen.

In the other greenhouse (Greenhouse 2), paprika plants (C. annuum L., variety 'Fairway') were cultivated on rockwool cubes with a planting density of 1.3 plants $/ \mathrm{m}^{2}(180 \mathrm{~cm}$ between rows and $30 \mathrm{~cm}$ between plants within a row). These paprika plants were seeded on 21 Aug. 2020, and transplanted onto the rockwool cubes on 10 Sept. 2020. The plants were pruned to two shoots, which were led with support strings tied to two parallel wires $2.0 \mathrm{~m}$ above the ground. Similar to the tomato canopy, a nutrient solution was prepared following the OAT SA prescription with an EC of 1.8 $\mathrm{dS} \cdot \mathrm{m}^{-1}$. This nutrient solution was supplied to the paprika plants intermittently every hour during the daytime and every 2 hours during the nighttime. Both the tomato and paprika cultivations ended on 8 July 2021.

\section{Measurements}

Canopy photosynthesis. The $A_{\mathrm{c}}$ of paprika and tomato canopies was measured to construct a model of canopy-scale photosynthetic responses to $I$. The measurements were performed according to the open-chamber method, which was modified from the method described by Nomura et al. (2020) (Fig. 2). Four open chambers, each being 1.2 $\mathrm{m}$ long, $1.2 \mathrm{~m}$ wide, and $2.4 \mathrm{~m}$ high, were constructed; two chambers were used for the paprika canopy, and the other two chambers were used for the tomato canopy. Four individual paprika plants were enclosed per chamber, and seven individual tomato plants were enclosed per chamber. Each chamber was covered with F-CLEAN Clear (AGC Green-Tech Co., Ltd.). The measurements continued for $18 \mathrm{~d}$, from 19 June to 6 July 2021. The leaf area index (LAI) of paprika and tomato canopies was estimated with an LAI-2200C (LI-COR Biosciences, Lincoln, NE) on 14 June 2021. The LAI values were 1.73 and 1.56 for the paprika and tomato canopies, respectively. $I$ at the top of the canopies was measured with a PPFD sensor (PAR-02; PREDE, Tokyo, Japan) installed inside each chamber during the chamber applications. Ambient air was continuously introduced into each chamber with a blower (San Ace 9CRA0912P0G001; Sanyo Denki, Tokyo, Japan $)$, and $A_{\mathrm{c}}\left(\mu \mathrm{mol} \cdot \mathrm{m}^{-2} \cdot \mathrm{s}^{-1}\right.$ based on ground area) was calculated according to the difference in $\mathrm{CO}_{2}$ concentrations $\left(C_{\mathrm{a}}\right)$ at the chamber inlet and outlet $\left(C_{\mathrm{a} \text {,in }}\right.$ and $C_{\mathrm{a} \text {,out }}$, respectively) multiplied by the airflow rate $\left(Q ; \mathrm{mol} \cdot \mathrm{s}^{-1}\right)$ :

$$
A_{\mathrm{c}}=Q\left(C_{\mathrm{a}, \text { in }}-C_{\mathrm{a}, \text { out }}\right) / S,
$$

where $S$ is the ground area. $S$ was calculated as the plant row interval $(1.8 \mathrm{~m})$ multiplied by the chamber length $(1.2 \mathrm{~m})$ to include the aisle width in the calculation of $S$ (i.e., $S=2.16 \mathrm{~m}^{2}$ ). $Q$ was set to $45 \mathrm{~m}^{3} \cdot \mathrm{h}^{-1}$, which corresponded to $\approx 5 \mathrm{~min}$ for the chamber air to be replaced entirely. In each greenhouse, $C_{\mathrm{a} \text {,in }}$ and $C_{\mathrm{a} \text {,out }}$ values, along with the water vapor concentrations at the inlet and outlet of each chamber ( $W_{\mathrm{a}, \text { in }}$ and $\left.W_{\mathrm{a}, \text { out }}\right)$, were measured with an infrared gas analyzer (LI850, LI-COR Biosciences), whose internal pump brought in the air at the two chambers' inlets and outlets sequentially at 1-min intervals. The air temperature $\left(T_{\mathrm{a}}\right)$ was also measured at the inlet and outlet of each chamber using T-type thermocouples. The atmospheric vapor pressure deficit (VPD) was computed based on the $W_{\mathrm{a}}$ and $T_{\mathrm{a}}$ values.

PPFD and other environmental elements. $I$ was measured outside and inside greenhouses and under shade nets to evaluate radiation losses due to both the greenhouse superstructures and shade nets. A PPFD sensor (PAR-02) was installed in the northwestern part of each of the two greenhouses on top of a horizontal beam $\approx 2.5 \mathrm{~m}$ above the ground (see Fig. 1A and B). This position was chosen to avoid shade created by the folded shade nets during periods of nonuse. The analog outputs from each PPFD sensor were recorded every 30 seconds using a datalogger (LR8431; Hioki E.E. Corporation, Nagano, Japan) and later averaged over 30 min. Another PPFD sensor (PAR-02) was installed in the middle of an open field, $\approx 100$ $\mathrm{m}$ away from the greenhouses. The analog outputs from this outside sensor were recorded every 2 min using a datalogger (MCR-4V; T\&D, Nagano, Japan) and later averaged over $30 \mathrm{~min}$. The measurements were conducted for $10 \mathrm{~d}$ in 2021: 17, 18, 22, 23, 24, 25, and 31 July, and 1, 7, and 8 Aug. During the experiment, one greenhouse was shaded with the shade net, while the other was unshaded, and the shaded and unshaded greenhouses were switched each day to

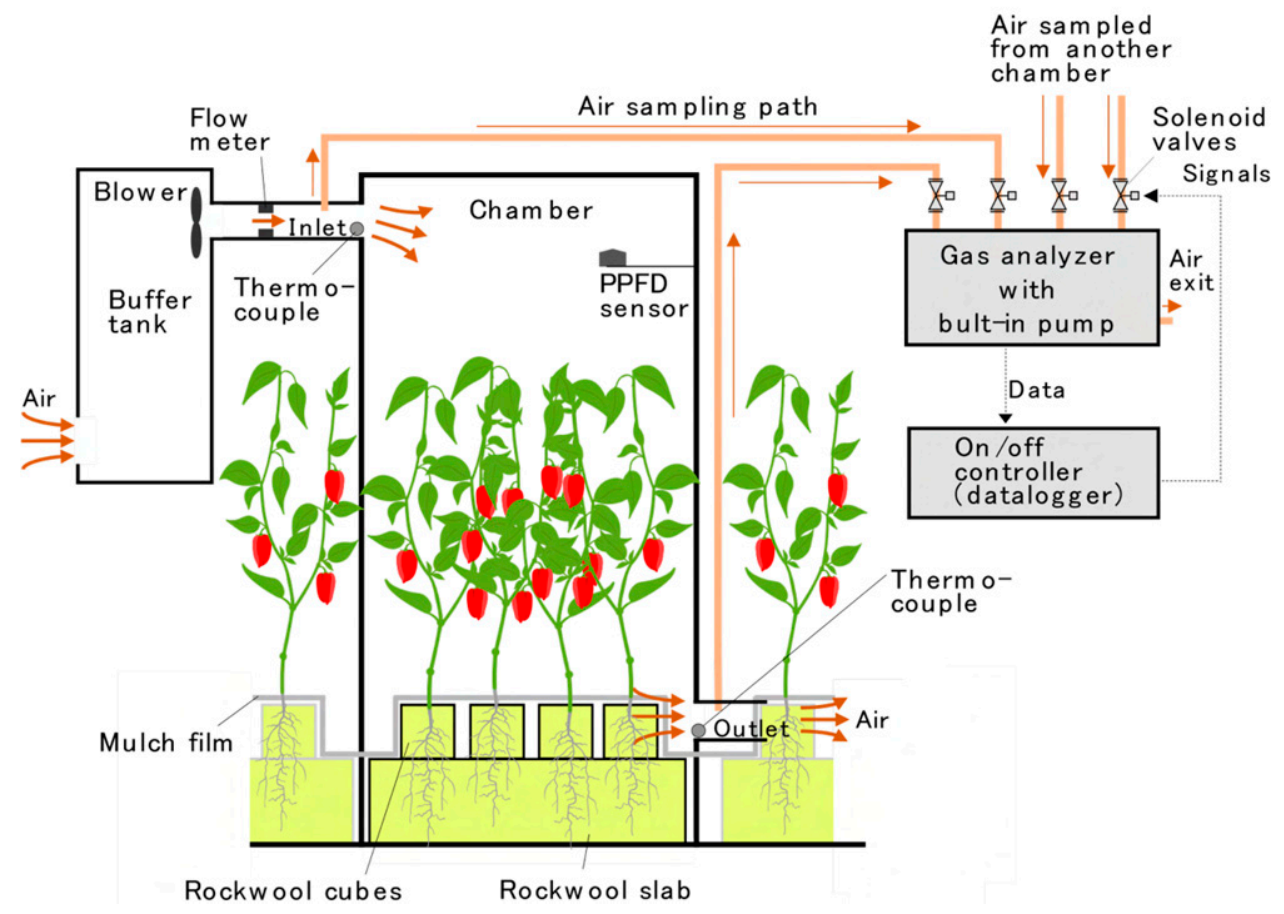

Fig. 2. Schematic view of the open-chamber system for measuring the net photosynthetic rates $\left(A_{\mathrm{c}}\right)$ of a crop canopy. $A_{\mathrm{c}}$ was estimated by multiplying the airflow rate with the difference in the $\mathrm{CO}_{2}$ concentrations between inlet and outlet air. The inlet and outlet air was sampled sequentially through switchable air sampling paths, and the $\mathrm{CO}_{2}$ concentrations were measured with an infrared gas analyzer. The infrared gas analyzer was connected to two chambers such that the $A_{\mathrm{c}}$ measurements were duplicated (only one chamber is shown in the figure). 
prevent any biases associated with differences in the two greenhouses. This operation of the shade nets was performed after sunset. Linear regression coefficients relating $I_{\text {out }}$ and $I_{\text {in }}$ as well as $I_{\text {out }}$ and $I_{\text {sh }}$ were derived based on the $I$ values obtained outside $\left(I_{\text {out }}\right)$ and inside the greenhouses $\left(I_{\text {in }}\right)$ and under the shade nets in the greenhouses $\left(I_{\mathrm{sh}}\right)$. In addition, each of the greenhouses was equipped with a set of environmental sensors (i.e., a pair of thermistors measuring dry- and wet-bulb temperatures and $\mathrm{CO}_{2}$ sensor; EyeFARM-box EB-500, Nippo, Saitama, Japan) in the center of the greenhouse.

\section{Calculations}

Canopy photosynthesis model. Based on the $A_{\mathrm{c}}$ and $I$ measurements using the open chambers, light-photosynthetic response curves ( $A_{\mathrm{c}}-I$ curves) at the canopy scale were obtained by fitting a nonrectangular hyperbola [Eq. (2)], which has been used to express light-photosynthetic response curves at the single-leaf scale (e.g., Hikosaka et al., 2016; Thornley, 2002) as

$A_{\mathrm{c}}=\frac{\phi I+A_{\max }-\sqrt{\left(\phi I+A_{\max }\right)^{2}-4 \phi I A_{\max } \theta}}{2 \theta}-R$,

where $A_{\max }$ is the light-saturated canopy photosynthetic rate, $\phi$ is the initial slope of the $A_{\mathrm{c}}-I$ curve, $\theta$ is a convexity term, and $R$ is the respiration rate in light. The values of $A_{\max }$, $\phi, \theta$, and $R$ were obtained by fitting Eq. [2] to the $A_{\mathrm{c}}-I$ relationships measured using the chamber system. This fitting was performed by minimizing the sum of squared errors between the measured and predicted $A_{\mathrm{c}}$ values using the Python lmfit package (version 1.0.1; Newville et al., 2014) based on the Levenberg-Marquardt method.

It should be noted that the use of the regression model [Eq. (2)] is not intended for constructing a predictive canopy photosynthesis model for use in other situations; we used the regression model to provide estimates of $A_{\mathrm{c}}$ based on our specific observations of $A_{\mathrm{c}}-I$ relationships. Thus, model parameters obtained through curve fitting will not be applicable to other cases if environmental conditions (e.g., temperature, humidity, and $\mathrm{CO}_{2}$ concentration) and the canopy structure (e.g., LAI) are widely different.

Simulation of canopy photosynthesis. The effects of shade nets on $A_{\mathrm{c}}$ were evaluated quantitatively using Eq. [2] with a set of parameters obtained from the curve fittings. Daytime responses of $A_{\mathrm{c}}$ to $I_{\mathrm{out}}, I_{\mathrm{in}}$, and $I_{\mathrm{sh}}$ were simulated based on $I_{\text {out }}$ values in typical sunny and cloudy days in the summer in Japan (i.e., $I_{\text {out }}$ measured on 18 and 31 July 2021). In this simulation, $I_{\text {in }}$ and $I_{\text {sh }}$ were predicted based on the linear relationships between $I_{\text {out }}$ and $I_{\text {in }}$ and between $I_{\text {out }}$ and $I_{\text {sh }}$, respectively.

\section{Results and Discussion}

\section{Canopy photosynthetic rates}

Figure 3 shows the changes in the $A_{\mathrm{c}}$ of the paprika canopy, along with the environmental

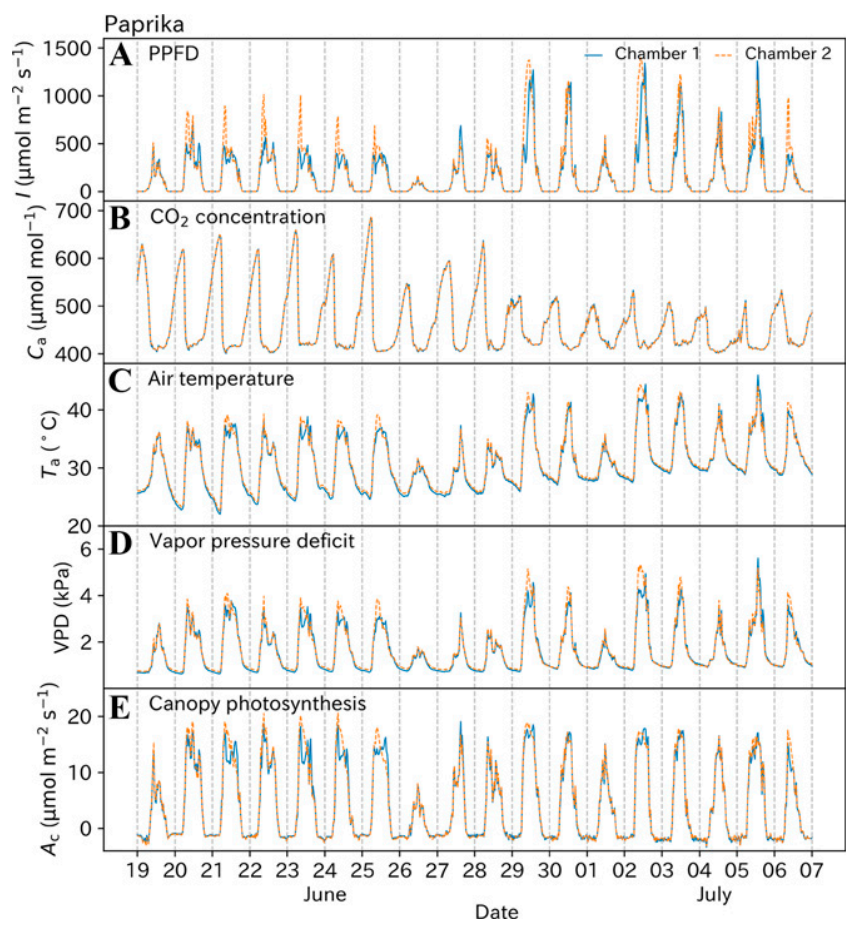

Fig. 3. Changes in the (A) photosynthetic photon flux density (PPFD; $I),(\mathbf{B}) \mathrm{CO}_{2}$ concentration $\left(C_{\mathrm{a}}\right)$, (C) air temperature $\left(T_{\mathrm{a}}\right)$, and (D) vapor pressure deficit (VPD) inside the chambers, and (E) canopy photosynthetic rate $\left(A_{\mathrm{c}}\right)$ of the paprika canopy. Measurements were duplicated using two open chambers.

elements measured inside the two chambers. During the daytime, $I, T_{\mathrm{a}}$, and VPD increased, whereas $C_{\mathrm{a}}$ decreased due to photosynthetic $\mathrm{CO}_{2}$ uptake by the canopy inside the greenhouse. The daytime averages of $I, C_{\mathrm{a}}, T_{\mathrm{a}}$, and VPD in one of the two chambers (Chamber 1

in Fig. 3) were $273 \pm 269\left(\mu \mathrm{mol} \cdot \mathrm{m}^{-2} \cdot \mathrm{s}^{-1}\right), 437$ $\pm 54\left(\mu \mathrm{mol} \cdot \mathrm{mol}^{-1}\right), 35 \pm 5\left({ }^{\circ} \mathrm{C}\right)$, and $2.08 \pm$ $1.0(\mathrm{kPa})$, respectively (the values after the plus-minus signs represent the standard deviations). As shown in Fig. 3, there were no considerable differences between the environments

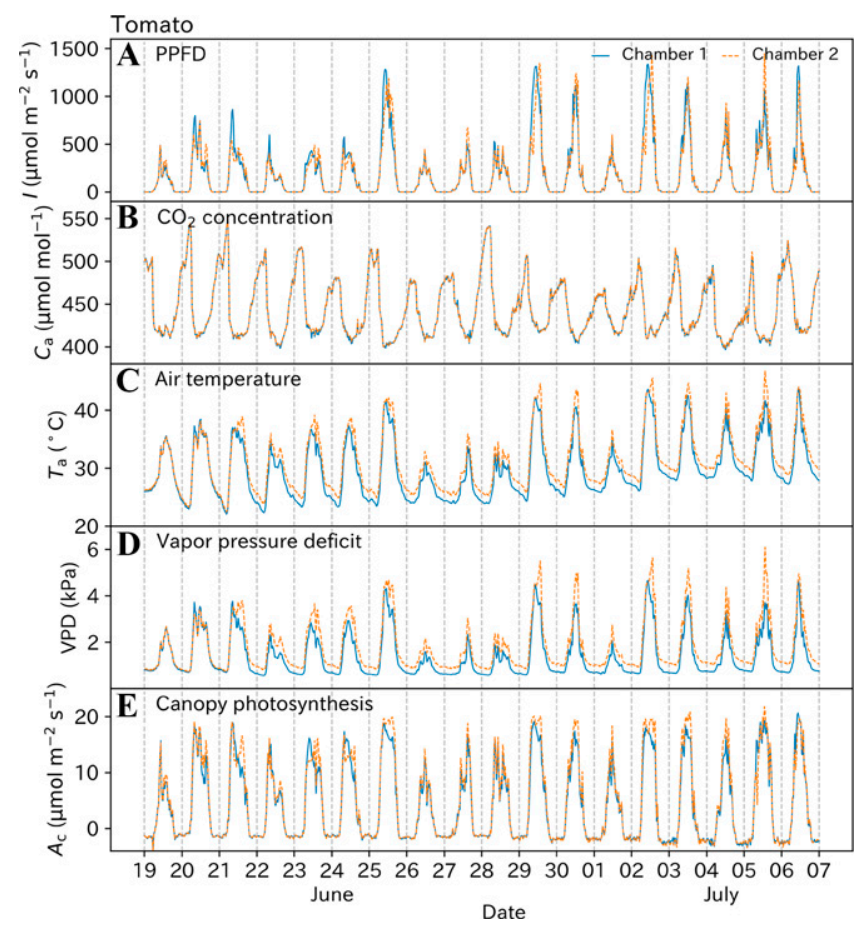

Fig. 4. Changes in the (A) photosynthetic photon flux density (PPFD; $I),(\mathbf{B}) \mathrm{CO}_{2}$ concentration $\left(C_{\mathrm{a}}\right)$, (C) air temperature $\left(T_{\mathrm{a}}\right)$, and $(\mathbf{D})$ vapor pressure deficit (VPD) inside the chambers, and (E) canopy photosynthetic rate $\left(A_{\mathrm{c}}\right)$ of the tomato canopy. Measurements were duplicated using two open chambers. 

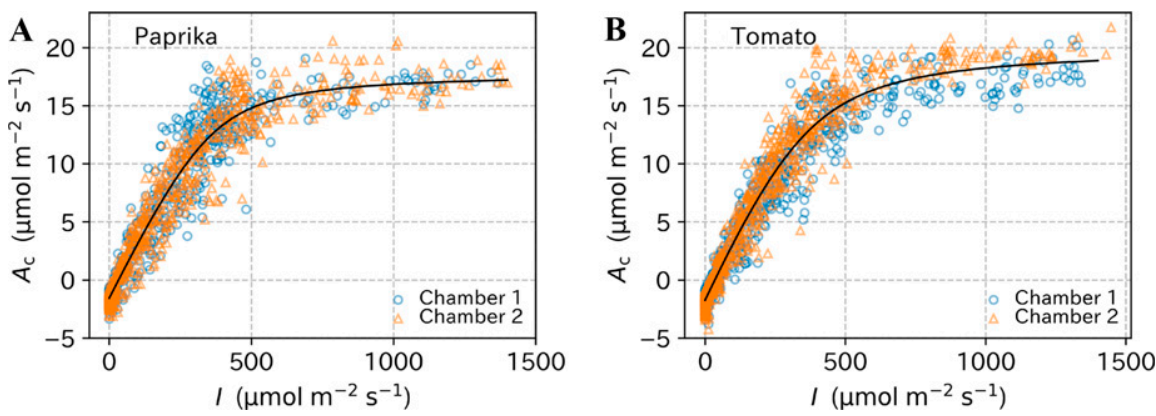

Fig. 5. Relationships between the canopy photosynthetic rate $\left(A_{\mathrm{c}}\right)$ and photosynthetic photon flux density (PPFD; $I$ ) measured for (A) paprika and (B) tomato canopies. For each fruit vegetable, measurements were duplicated in two different canopies using two open chambers (the circles and triangles indicate the different canopies). The curves (solid lines) were obtained by fitting Eq. [2] to the observations. The measurements were conducted from 19 June to 6 July 2021.

in the duplicated chambers. As a result of these diurnal changes in the environmental conditions, $A_{\mathrm{c}}$ changed dynamically during the daytime. The tomato canopy inside the chambers had environmental conditions similar to those of the paprika canopy (Fig. 4); the daytime averages of $I, C_{\mathrm{a}}, T_{\mathrm{a}}$, and VPD in one of the chambers (Chamber 1 in Fig. 4) were $316 \pm$ $307\left(\mu \mathrm{mol} \cdot \mathrm{m}^{-2} \cdot \mathrm{s}^{-1}\right), 428 \pm 27\left(\mu \mathrm{mol} \cdot \mathrm{mol}^{-1}\right)$, $35 \pm 5\left({ }^{\circ} \mathrm{C}\right)$, and $2.3 \pm 1.1(\mathrm{kPa})$, respectively.

Figure 5 shows the $A_{\mathrm{c}}-I$ curves for the paprika and tomato canopies. The $A_{\mathrm{c}}-I$ curves for both species showed the typical shape of photosynthetic nonlinear rectangular hyperbolae represented by Eq. [2]. The duplicate measurements in each canopy provided almost identical results (i.e., in Fig. 5A and $\mathrm{B}$, the circle and triangle markers indistinguishably overlap), suggesting homogeneity in the paprika and tomato canopies. $A_{\mathrm{c}}$ increased almost linearly with $I$ up to $I=450$ $\mu \mathrm{mol} \cdot \mathrm{m}^{-2} \cdot \mathrm{s}^{-1}$ and then showed signs of light saturation. This response of $A_{\mathrm{c}}$ to $I$ can be explained by two distinct limiting processes, namely, the regeneration and carboxylation of ribulose-1,5-bisphosphate (RuBP) (Farquhar et al., 1980). The linear increase in $A_{\mathrm{c}}$ in the low $I$ region indicates that the photosynthetic process was limited by RuBP regeneration, which ultimately depends on incoming $I$. In contrast, the apparent saturation of $A_{\mathrm{c}}$ in the high- $I$ region indicates that the photosynthetic process was limited by RuBP carboxylation, which depends mainly on the $\mathrm{CO}_{2}$ concentration. During the experiment, the average daytime $C_{\mathrm{a}, \text { in }}$ value was $\approx 430 \mu \mathrm{mol} \cdot \mathrm{mol}^{-1}$, which is within the normal $\mathrm{CO}_{2}$ concentration range observed in a greenhouse. If the $\mathrm{CO}_{2}$ concentration was artificially elevated, the saturating $I$ would have been higher than $450 \mu \mathrm{mol} \cdot \mathrm{m}^{-2} \cdot \mathrm{s}^{-1}$ because a higher $\mathrm{CO}_{2}$ concentration alleviates the $\mathrm{CO}_{2}$ limitation of $A_{\mathrm{c}}$ that occurs under high $I$ conditions (Stitt, 1991). However, it should be noted that $A_{\mathrm{c}}$ continued to increase slightly even over $I=450 \mu \mathrm{mol} \cdot \mathrm{m}^{-2} \cdot \mathrm{s}^{-1}$. This slight increase in $A_{\mathrm{c}}$ can be attributed to the lower leaves in the canopy, which are not light saturated due to the shading of the upper leaves (Nomura et al., 2021b). With an increase in $I$ at the top of the canopy, these lower leaves could have received stronger $I$ and increased the $A_{\mathrm{c}}$.

During the experiment, the average daytime temperature inside the chambers was $\approx 35^{\circ} \mathrm{C}$ and sometimes exceeded $40^{\circ} \mathrm{C}$, with

Table 1. Parameter values of the nonrectangular hyperbola [Eq. (2)] obtained by least-square fitting to the measured $A_{\mathrm{c}}-I$ curves for the paprika and tomato canopies (Fig. 5). The estimates of the standard errors of the parameters are also shown after the plus-minus signs.

\begin{tabular}{lcr}
\hline Parameter & Paprika & Tomato \\
\hline$A_{\max }\left(\mu \mathrm{mol} \cdot \mathrm{m}^{-2} \cdot \mathrm{s}^{-1}\right)$ & $19.4 \pm 0.26$ & $21.8 \pm 0.30$ \\
$\theta(-)$ & $0.91 \pm 0.013$ & $0.86 \pm 0.018$ \\
$\Phi(-)$ & $0.048 \pm 0.001$ & $0.051 \pm 0.001$ \\
$R\left(\mu \mathrm{mol} \cdot \mathrm{m}^{-2} \cdot \mathrm{s}^{-1}\right)$ & $1.56 \pm 0.050$ & $1.73 \pm 0.048$ \\
\hline
\end{tabular}

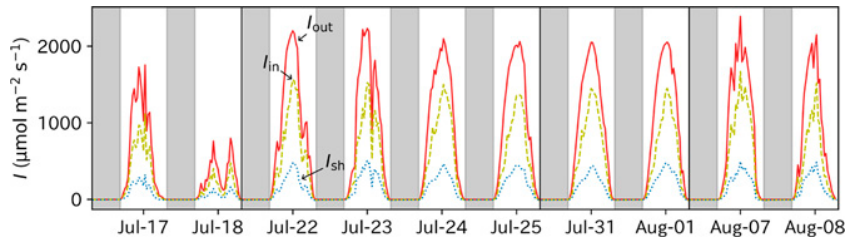

Fig. 6. Daily changes in the photosynthetic photon flux density (PPFD; $I)$ measured outside $\left(I_{\text {out }}\right.$; solid line) and inside the greenhouses $\left(I_{\text {in }}\right.$; broken line) and under the shade nets in the greenhouses $\left(I_{\text {sh }}\right.$; dotted line). The measurements were conducted during four periods between 17 July and 8 Aug. 2021; these periods are separated in the figure by the solid vertical lines. The gray-shaded regions indicate nighttime. Thirty-minute averages are shown.

a maximum of $\approx 45^{\circ} \mathrm{C}$ (see Figs. 3 and 4 ). Such high temperatures, however, did not cause any explicit $A_{\mathrm{c}}$ drops, which occur at the molecular and single-leaf scales (Mathur et al., 2014; Medlyn et al., 2002; Wise et al., 2004).

Table 1 summarizes the parameter values of the nonrectangular hyperbola [Eq. (2)] obtained by least-square fitting to the measured $A_{\mathrm{c}}-I$ curves for the paprika and tomato canopies shown in Fig. 5. The estimated standard errors of the model parameters were small compared with the best-fit parameters (the standard error/best-fit parameter was less than $3.2 \%$ ), indicating that the model parameters were identified well. The optimized parameters slightly differed between the two species, which can be attributed to differences in 1) the photosynthetic properties of individual leaves in each canopy [e.g., different leaf-scale parameters such as $V_{\text {cmax }}$ and $J_{\max }$ (Farquhar et al., 1980; von Caemmerer, 2000)]; 2) the distributions of photosynthetic properties within each canopy (Hirose and Werger, 1987); and 3) canopy structure, including the LAI, leaf angle distribution, and leaf clumping (Chen et al., 2012; Lawlor, 1995; Wang et al., 2007).

\section{Effects of the greenhouse superstructures and shade nets on incoming PPFD}

Figure 6 shows daily changes in $I_{\text {out }}, I_{\text {in }}$, and $I_{\mathrm{sh}}$. $I_{\text {out }}$ underwent diurnal changes caused by the movement of the sun and clouds. The first $2 \mathrm{~d}$ of the experimental period (17 and 18 July) were cloudy and rainy, but the other days were largely sunny. $I_{\text {out }}$ reached a maximum value of 2400 $\mu \mathrm{mol} \cdot \mathrm{m}^{-2} \cdot \mathrm{s}^{-1}$ around noon on 7 Aug.

In comparison with $I_{\text {out }}, I_{\text {in }}$ was much smaller. This reduction in $I_{\text {in }}$ was partly due to the reflection and absorption of the incoming $P A R$ by the cover material. In addition, $I_{\text {in }}$ was reduced because of interceptions by the greenhouse structural elements (e.g., the ridges, trusses, and folded shade nets), which prevented some of the PAR transmitted by the cover from reaching the PPFD sensor (Matsuda et al., 2020). Because the cover material has a diffusing property that scatters photon flux in various directions, any greenhouse structures above the PPFD sensor could have reduced $I_{\text {in }}$, even if these structures did not occur along the straight line between the sun and the PPFD sensor. $I_{\text {in }}$ showed a strong linear relationship $\left(R^{2}=\right.$ 0.95 ) with $I_{\text {out }}$ (Fig. 7). This strong linear relationship also may be attributed to the diffusing property of the cover material, which caused the incoming photon flux to be largely uniform. The regression coefficient (i.e., slope) between $I_{\text {in }}$ and $I_{\text {out }}$ was 0.61 , indicating that $I$ was reduced by almost $40 \%$ due to the greenhouse cover and structures. This $I_{\text {in }} / I_{\text {out }}$ value $(0.61)$ is substantially lower than a laboratory-measured transmissivity value of 0.81 (hemispherical transmission; Hemming et al., 2008). These results indicate that a considerable amount of incoming $P A R$ was 


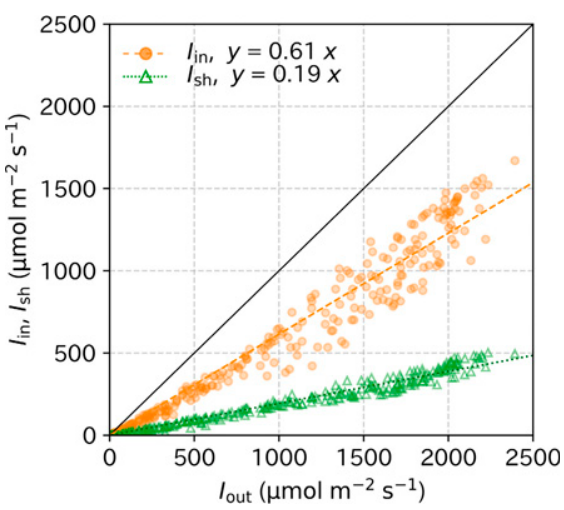

Fig. 7. Relationships between the photosynthetic photon flux density (PPFD; $I$ ) measured outside the greenhouses $\left(I_{\text {out }}\right)$, inside both greenhouses $\left(I_{\text {in }}\right)$ and under the shade nets in the greenhouses $\left(I_{\mathrm{sh}}\right)$. These relationships were obtained based on the 30 -min average values. The regression lines were drawn with forced zero intercepts. A 1:1 line is displayed for reference.

blocked by the greenhouse superstructures. In addition, it is possible that the transmission of the cover material was reduced by tiny particles (e.g., dust) attached to the cover material. The value of 0.61 was consistent with that found in a previous study (Giacomelli and Roberts, 1993) reporting the average daily transmission of $P A R$ measured inside greenhouses with four different covering materials (i.e., single-layer glass, acrylic, double-layer glass, and double-layer polyethylene, whose transmissions were $0.56,0.55$, 0.56 , and 0.45 , respectively, near the plant canopy).

The shade nets further reduced the incoming $I ; I_{\text {sh }}$ was only $19 \%$ of $I_{\text {out }}$ (Fig. 7) and had a strong linear relationship with $I_{\text {out }}\left(R^{2}=\right.$ 0.96). This strong linear relationship can be used to predict the amount of $I_{\mathrm{sh}}$ based on $I_{\text {out }}$ in this specific setting. $I_{\text {sh }}$ was also linearly correlated with $I_{\mathrm{in}} ; I_{\mathrm{sh}}$ was only $31 \%$ of $I_{\text {in }}$ (not shown in the figures). This value was consistent with the manufacturer's specifications, in which the transmissivities for direct light and diffuse light were $35 \%$ and $32 \%$, respectively.

\section{Effects of the shade nets on the greenhouse temperature}

Figure $8 \mathrm{~A}$ shows the daily changes in the temperature $(T)$ measured outside the greenhouses $\left(T_{\text {out }}\right)$ and inside the greenhouses without $\left(T_{\mathrm{in}}\right)$ and with the shade nets $\left(T_{\mathrm{sh}}\right)$. A clear diurnal pattern in $T$ was found; upon sunrise, $T_{\text {out }}, T_{\text {in }}$, and $T_{\text {sh }}$ began to steeply increase from $\approx 23^{\circ} \mathrm{C}$ to more than $30^{\circ} \mathrm{C}$ during the midday hours (i.e., between 1000 and $1500 \mathrm{HR}$ ) and then gradually decreased until the next sunrise. Throughout the experimental period, $T$ showed an overall increasing trend.

Figure 8B shows the differences in $T$ inside and outside the greenhouses. Both $T_{\text {in }}-T_{\text {out }}$ and $T_{\text {sh }}-T_{\text {out }}$ were positive during the daytime, indicating that the air inside the greenhouses was warmer than the outside air.

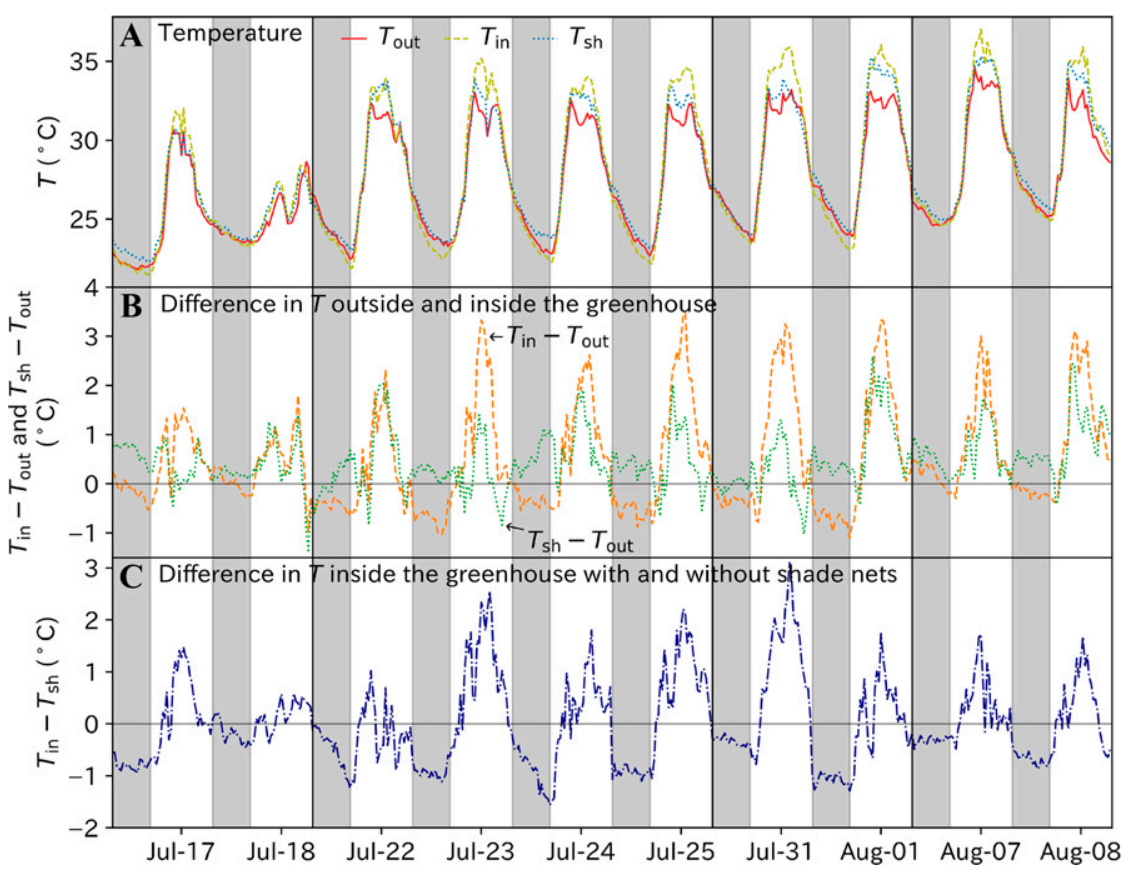

Fig. 8. (A) Daily changes in temperature $(T)$ measured outside ( $T_{\text {out }}$; solid line) and inside the greenhouses ( $T_{\mathrm{in}}$; broken line) and under the shade nets in the greenhouses ( $T_{\text {sh; }}$ dotted line). (B) Increases in $T$ inside the greenhouses in comparison with the outside $T$ (i.e., $T_{\mathrm{in}}-T_{\text {out }}$ and $T_{\mathrm{sh}}-$ $T_{\text {out }}$ for greenhouses with the shade nets and without the shade nets, respectively). (C) Differences in $T$ with and without the shade nets $\left(T_{\mathrm{in}}-T_{\mathrm{sh}}\right)$. The measurements were performed during four periods between 17 July and 8 Aug. 2021; these periods are separated in the figure by the solid vertical lines. The gray-shaded regions indicate nighttime.
During the midday hours, the average difference in $T$ outside and inside the greenhouses without shade nets $\left(T_{\text {in }}-T_{\text {out }}\right)$ was $2.0^{\circ} \mathrm{C}$, with a maximum value of $3.5^{\circ} \mathrm{C}$. With the application of shade nets, the midday average difference in $T\left(T_{\mathrm{sh}}-T_{\text {out }}\right)$ was reduced to $1.0^{\circ} \mathrm{C}$, with a maximum value of $2.6^{\circ} \mathrm{C}$, indicating an air-cooling effect of the shade nets.

Figure $8 \mathrm{C}$ shows the differences in $T$ inside the greenhouses with and without shade nets (i.e., $T_{\text {in }}-T_{\text {sh }}$ ). During the midday hours, $T_{\text {in }}-T_{\text {sh }}$ was almost always positive, with an average value of $0.98^{\circ} \mathrm{C}$, indicating that the greenhouse air without shade nets was nearly $1{ }^{\circ} \mathrm{C}$ higher than that when shade nets were present. This temperature reduction by the shade nets was caused by the improvement of greenhouse heat balance due to the reduction in incoming solar radiation, as indicated ation energy can be reduced by $81 \%$ when the shade nets are used (assuming that $I$ is proportional to the energy flux density in $\mathrm{W} \cdot \mathrm{m}^{-2}$ ). in Fig. 7, which shows that incoming solar radi-
Because incoming solar radiation is the dominant heat source warming the greenhouse air during the summer (Kittas et al., 2005 ), such a considerable reduction in radiation by shade nets can contribute to a reduction in $T$. In addition, such a reduction in solar radiation by the shade nets would cause a reduction in the apparent $T$ (i.e., the temperature equivalent perceived by humans) experienced by workers inside the greenhouse. In contrast to the positive daytime $T_{\text {in }}-T_{\mathrm{sh}}$, the nighttime $T_{\text {in }}-T_{\mathrm{sh}}$ was negative (i.e., the air temperature was higher when the shade nets were present than when they were absent), indicating that the shade nets trap longwave radiation from the ground below. This warming effect of shade nets can help maintain a higher nighttime $T$ in the winter (Ahemd et al., 2016).

\section{Effects of greenhouse superstructures and shade nets on canopy photosynthesis \\ Using Eq. [2] and the parameters obtained} from the least-square curve fitting, we estimated
Table 2. Effects of the greenhouse superstructures and shade nets on the photosynthetic photon flux density $(\mathrm{PPFD} ; I)$ and canopy photosynthetic rates $\left(A_{\mathrm{c}}\right)$ simulated using Eq. [2] and parameters for the paprika and tomato canopies on a sunny day. Cumulative values of $I$ and $A_{\mathrm{c}}$ during the daytime are shown in $\mathrm{mol} \cdot \mathrm{m}^{-2} \cdot \mathrm{d}^{-1}$ (middle columns), and these values were compared as proportions (right columns). I values measured outside on 31 July 2021 were used as the inputs.

\begin{tabular}{lcccccccc}
\hline & \multicolumn{2}{c}{ Simulated value $\left(\mathrm{mol} \cdot \mathrm{m}^{-2} \cdot \mathrm{d}^{-1}\right)$} & & \multicolumn{3}{c}{ Proportion } \\
\cline { 2 - 3 } & Outside & Inside & Shaded & & Inside/outside & Shaded/outside & Shaded/inside \\
\hline$I$ & 58.3 & 35.6 & 11.1 & & 0.61 & 0.19 & 0.31 \\
$A_{\mathrm{c}}$ (paprika) & 0.728 & 0.666 & 0.376 & & 0.91 & 0.52 & 0.57 \\
$A_{\mathrm{c}}$ (tomato) & 0.790 & 0.710 & 0.379 & & 0.90 & 0.48 & 0.53 \\
\hline
\end{tabular}


Table 3. Effects of the greenhouse superstructures and shade nets on $I$ and $A_{\mathrm{c}}$ simulated for a cloudy day. $I$ values measured outside on 18 July 2021 were used as the inputs. The other simulation conditions were the same as those for Table 2 .

\begin{tabular}{lccccccc}
\hline & \multicolumn{2}{c}{ Simulated value $\left(\mathrm{mol} \cdot \mathrm{m}^{-2} \cdot \mathrm{d}^{-1}\right)$} & & \multicolumn{3}{c}{ Proportion } \\
\cline { 2 - 3 } & Outside & Inside & Shaded & & Inside/outside & Shaded/outside & Shaded/inside \\
\hline$I$ & 16.5 & 10.0 & 3.1 & & 0.61 & 0.19 & 0.31 \\
$A_{\mathrm{c}}$ (paprika) & 0.485 & 0.334 & 0.065 & & 0.69 & 0.13 & 0.20 \\
$A_{\mathrm{c}}$ (tomato) & 0.499 & 0.337 & 0.063 & & 0.68 & 0.13 & 0.19 \\
\hline
\end{tabular}

to what extent $A_{\mathrm{c}}$ would be reduced due to the greenhouse superstructures and shade nets on typical sunny and cloudy summer days (Tables 2 and 3, respectively). As shown in Fig. 9 (i.e., a simulation on the sunny day), the effects of the greenhouse superstructures and shade nets on $I$ were remarkable; only $61 \%$ and $19 \%$ of $I_{\text {out }}$ was measured below the greenhouse superstructures and shade nets, respectively (Table 2). However, as shown in Fig. 9B for the paprika canopy, the simulated effects of the greenhouse superstructures and shade nets on $A_{\mathrm{c}}$ were much milder on a sunny summer day (31 July 2021); $A_{\mathrm{c}}$ in the greenhouse $\left(A_{\mathrm{c}, \text { in }}\right)$ and under the shade nets $\left(A_{\mathrm{c}, \mathrm{sh}}\right)$ corresponded to $91 \%$ and $52 \%$ of the outside $A_{\mathrm{c}}\left(A_{\mathrm{c}, \text { out }}\right)$, respectively (for the tomato canopy, $A_{\mathrm{c}, \text { in }}$ and $A_{\mathrm{c}, \mathrm{sh}}$ corresponded to $90 \%$ and $48 \%$ of $A_{\text {c,out; }}$, see Table 2). These results were attributed to the saturating $A_{\mathrm{c}}-I$ responses (Fig. 5), in which $A_{\mathrm{c}}$ was saturating over $I=450 \mu \mathrm{mol} \cdot \mathrm{m}^{-2} \cdot \mathrm{s}^{-1}$. In comparison with this threshold value, $I_{\text {out }}$ is almost always excessive on a typical sunny summer day in Japan except in the very early morning and evening. Because of this saturating nature of photosynthesis, the $39 \%$ reduction in I by the greenhouse superstructures caused only an $\approx 9 \%$ reduction in $A_{\mathrm{c}}$. However, the reduction in $A_{\mathrm{c}}$ caused by the shade nets was not

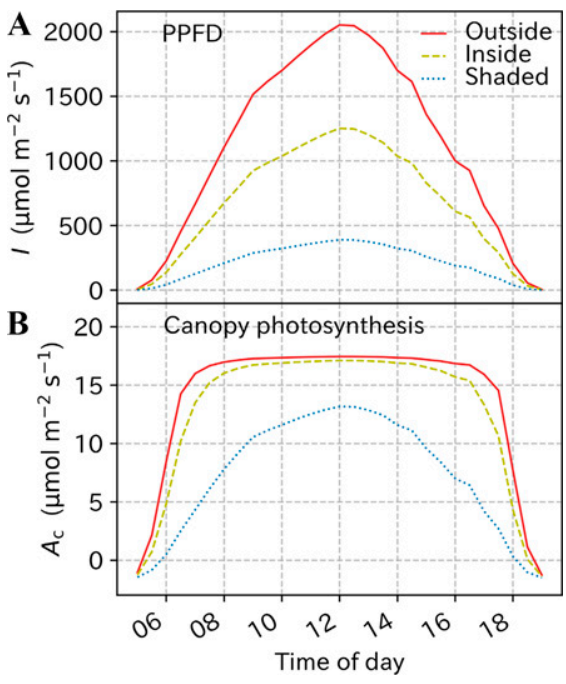

Fig. 9. Simulation of typical diurnal responses of canopy photosynthetic rates $\left(A_{\mathrm{c}}\right)$ to photosynthetic photon flux density (PPFD; $I)$. I inside a greenhouse and under a shade net was estimated from outside $I$ measured on 31 July 2021, using the linear regression equations shown in Fig. 7. With these $I$ values as the inputs, $A_{\mathrm{c}}$ was estimated using Eq. [2] with the parameters obtained for the paprika canopy (Table 1). marginal; for the paprika and tomato canopies, $A_{\mathrm{c}, \mathrm{sh}}$ was only $\approx 57 \%$ and $53 \%$ of $A_{\mathrm{c} \text {,in }}$, respectively (Table 2).

Compared with the high $I$ conditions simulated in Fig. 9 and Table 2, the loss of $A_{\mathrm{c}}$ due to greenhouse superstructures and shade nets is more serious under low $I$ conditions. $A_{\mathrm{c}, \text { in }} / A_{\mathrm{c}, \text { out }}$ simulated on a cloudy day (18 July 2021 , see Fig. 6) was only $69 \%$ for the paprika canopy (Table 3). This value was much lower than that for the sunny day (i.e., $91 \%$ ). The lower value of $A_{\mathrm{c}, \text { in }} / A_{\mathrm{c}, \text { out }}$ on a cloudy day (i.e., low $I$ ) is not surprising, as $A_{\mathrm{c}}$ is sensitive to $I$ under low $I$ conditions (i.e., $A_{\mathrm{c}}$ responds to $I$ linearly under low $I$ conditions; see Fig. 5). Thus, the negative effect of greenhouse superstructures on $A_{\mathrm{c}}$ would be more considerable in winter, where $I$ tends to be much lower than that in summer (Marcelis et al., 2006). The application of the shade nets can further reduce $A_{\mathrm{c}}$; on the cloudy day, $A_{\mathrm{c}, \mathrm{sh}} / A_{\mathrm{c}, \text { out }}$ was simulated to be only $13 \%$ for both the paprika and tomato canopies (Table 3).

A good strategy for using shade nets is to use them only during the high $I$ period (Kläring and Krumbein, 2013). For example, if the usage of the shade nets was limited to 0800 until $1600 \mathrm{HR}, A_{\mathrm{c}, \mathrm{sh}}$ could reach $76 \%$ and $71 \%$ of $A_{\mathrm{c}, \text { in }}$ for the paprika and tomato canopies on a sunny day (data not shown). Such a limitation of shade net usage needs to be considered together with the working environment of human workers, because working in a hot greenhouse environment is a demanding and often dangerous task. To optimize the use of shade nets, future research should involve a more sophisticated analysis integrating detailed models that can estimate the temperature effects on $A_{\mathrm{c}}$ (e.g., Nomura et al., 2021a) and physics-based greenhouse climate models (Sethi et al., 2013) that can simulate the dynamic change in temperature in the presence and absence of shade nets.

\section{Literature Cited}

Ahemd, H.A., A.A. Al-Faraj, and A.M. Abdel-Ghany. 2016. Shading greenhouses to improve the microclimate, energy and water saving in hot regions: A review. Scientia Hort. 201:36-45, https://doi.org/10.1016/j.scienta.2016. 01.030 .

Ainsworth, E.A. and S.P. Long. 2005. What have we learned from 15 years of free-air $\mathrm{CO}_{2}$ enrichment (FACE)? A meta-analytic review of the responses of photosynthesis, canopy properties and plant production to rising $\mathrm{CO}_{2}$. New Phytol. 165:351-372, https://doi.org/ 10.1111/j.1469-8137.2004.01224.x.
Baeza, E., S. Hemming, and C. Stanghellini. 2020. Materials with switchable radiometric properties: Could they become the perfect greenhouse cover? Biosyst. Eng. 193:157-173, https://doi. org/10.1016/j.biosystemseng.2020.02.012.

Bisbis, M., N. Gruda, and M. Blanke. 2019. Securing horticulture in a changing climate- $\mathrm{A}$ mini review. Horticulturae 5:56, https://doi.org/10.3390/ horticulturae 5030056 .

Castellano, S., G. Scarascia Mugnozza, G. Russo, D. Briassoulis, A. Mistriotis, S. Hemming, and D. Waaijenberg. 2008. Plastic nets in agriculture: A general review of types and applications. Appl. Eng. Agr. 24:799-808, https://doi. org/10.13031/2013.25368.

Chen, J.M., G. Mo, J. Pisek, J. Liu, F. Deng, M. Ishizawa, and D. Chan. 2012. Effects of foliage clumping on the estimation of global terrestrial gross primary productivity. Global Biogeochem. Cycles 26:1-18, https://doi.org/10.1029/ 2010GB003996.

Farquhar, G.D., S. von Caemmerer, and J.A. Berry. 1980. A biochemical model of photosynthetic $\mathrm{CO}_{2}$ assimilation in leaves of $\mathrm{C} 3$ species. Planta 149:78-90.

Giacomelli, G.A. and W.J. Roberts. 1993. Greenhouse covering systems. HortTechnology 3: 50-58, https://doi.org/10.21273/horttech.3.1.50.

Hemming, S., V. Mohammadkhani, and T. Dueck. 2008. Diffuse greenhouse covering materials Material technology, measurements and evaluation of optical properties. Acta Hort. 797: 469-476, https://doi.org/10.17660/actahortic.2008. 797.68.

Hernández, V., P. Hellín, J. Fenoll, and P. Flores. 2019. Interaction of nitrogen and shading on tomato yield and quality. Scientia Hort. 255:255-259, https://doi.org/10.1016/j.scienta. 2019.05.040.

Hernández, V., P. Hellín, J. Fenoll, I. Garrido, J. Cava, and P. Flores. 2015. Impact of shading on tomato yield and quality cultivated with different $\mathrm{n}$ doses under high temperature climate. Procedia Environ. Sci. 29:197-198, https://doi. org/10.1016/j.proenv.2015.07.259.

Hikosaka, K., K. Noguchi, and I. Terashima. 2016. Modeling leaf gas exchange, p. 61-100. In: K. Hikosaka, Ü. Niinemets, and N.P.R. Anten (eds.). Canopy photosynthesis: From basics to applications. Springer, Berlin. https://doi.org/ 10.1007/978-94-017-7291-4_3.

Hirose, T. and M.J.A. Werger. 1987. Maximizing daily canopy photosynthesis with respect to the leaf nitrogen allocation pattern in the canopy. Oecologia 72:520-526, https://doi.org/10.1007/ BF00378977.

Kitta, E. and N. Katsoulas. 2020. Effect of shading on photosynthesis of greenhouse hydroponic cucumber crops. Ital. J. Agrometeorol. 2020: 41-48, https://doi.org/10.13128/ijam-871.

Kittas, C., M. Karamanis, and N. Katsoulas. 2005. Air temperature regime in a forced ventilated greenhouse with rose crop. Energy Build. 37: 807-812, https://doi.org/10.1016/j.enbuild.2004. 10.009

Kläring, H.P. and A. Krumbein. 2013. The effect of constraining the intensity of solar radiation on the photosynthesis, growth, yield and product quality of tomato. J. Agron. Crop Sci. 199:351-359, https://doi.org/10.1111/jac.12018.

Lawlor, D.W. 1995. Photosynthesis, productivity and environment. J. Expt. Bot. 46:1449-1461, https://doi.org/10.1093/jxb/46.special_issue.1449.

Li, T., E. Heuvelink, T.A. Dueck, J. Janse, G. Gort, and L.F.M. Marcelis. 2014. Enhancement of crop photosynthesis by diffuse light: Quantifying the contributing factors. Ann. Bot. 114: 145-156, https://doi.org/10.1093/aob/mcu071. 
López-Marín, J., A. Gálvez, A. González, C. Egea-Gilabert, and J.A. Fernández. 2012. Effect of shade on yield, quality and photosynthesis-related parameters of sweet pepper plants. Acta Hort. 956:545-552, https://doi.org/ 10.17660/ActaHortic.2012.956.65.

Marcelis, L.F.M., A.G.M. Broekhuijsen, E. Meinen, E.M.F.M. Nijs, and M.G.M. Raaphorst. 2006. Quantification of the growth response to light quantity of greenhouse grown crops. Acta Hort. 711:97-103, https://doi.org/10.17660/actah ortic.2006.711.9.

Masabni, J., Y. Sun, G. Niu, and P. Del Valle. 2016. Shade effect on growth and productivity of tomato and chili pepper. HortTechnology 26:344-350, https://doi.org/10.21273/horttech.26. 3.344.

Mathur, S., D. Agrawal, and A. Jajoo. 2014. Photosynthesis: Response to high temperature stress. J. Photochem. Photobiol. B. 137:116-126, https:// doi.org/10.1016/j.jphotobiol.2014.01.010.

Matsuda, S., H. Yoshikoshi, T. Suzuki, Y. Ohta, A. Chiba, H. Arima, H. Kumagai, D. Yasutake, and M. Kitano. 2020. Calculation of the irradiance of solar radiation in a greenhouse with a complex structure using a diagram for sky view factor. J. Agr. Meteorol. 76:44-52, https://doi. org/10.2480/agrmet.D-19-00043.

Medlyn, B.E., E. Dreyer, D. Ellsworth, M. Forstreuter, P.C. Harley, M.U.F. Kirschbaum, X. Le Roux, P. Montpied, J. Strassemeyer, A. Walcroft, K. Wang, and D. Loustau. 2002. Temperature response of parameters of a biochemically based model of photosynthesis. II. A review of experimental data. Plant Cell Environ. 25:1167-1179, https://doi.org/10.1046/ j.1365-3040.2002.00891.x.
Newville, M., T. Stensitzki, D.B. Allen, and A. Ingargiola. 2014. LMFIT: Non-linear leastsquare minimization and curve-fitting for python Zenodo, https://doi.org/10.5281/ZENODO.11813.

Nomura, K., A. Takada, H. Kunishige, Y. Ozaki, T. Okayasu, D. Yasutake, and M. Kitano. 2020. Long-term and continuous measurement of canopy photosynthesis and growth of spinach. Environ. Control Biol. 58:21-29, https:// doi.org/10.2525/ecb.58.21.

Nomura, K., D. Yasutake, T. Kaneko, T. Iwao, T. Okayasu, Y. Ozaki, M. Mori, and M. Kitano. 2021a. Long-term estimation of the canopy photosynthesis of a leafy vegetable based on greenhouse climate conditions and nadir photographs. Scientia Hort. 289:110433, https://doi. org/10.1016/j.scienta.2021.110433.

Nomura, K., D. Yasutake, T. Kaneko, A. Takada, T. Okayasu, Y. Ozaki, M. Mori, and M. Kitano. 2021b. Long-term compound interest effect of $\mathrm{CO}_{2}$ enrichment on the carbon balance and growth of a leafy vegetable canopy. Scientia Hort. 283:110060, https://doi.org/10.1016/ j.scienta.2021.110060.

Pearson, S., A.E. Wheldon, and P. Hadley. 1995. Radiation transmission and fluorescence of nine greenhouse cladding materials. J. Agr. Eng. Res. 62:61-69, https://doi.org/10.1006/jaer.1995.1063.

Prior, S.A., G. Brett Runion, S. Christopher Marble, H.H. Rogers, C.H. Gilliam, and H. Allen Torbert. 2011. A review of elevated atmospheric $\mathrm{CO}_{2}$ effects on plant growth and water relations: Implications for horticulture. HortScience 46:158-162, https://doi.org/ 10.21273/hortsci.46.2.158.

Sethi, V.P., K. Sumathy, C. Lee, and D.S. Pal. 2013. Thermal modeling aspects of solar greenhouse microclimate control: A review on heating technologies. Sol. Energy 96:56-82, https://doi.org/10.1016/j.solener.2013.06.034.

Stitt, M. 1991. Rising $\mathrm{CO}_{2}$ levels and their potential significance for carbon flow in photosynthetic cells. Plant Cell Environ. 14:741-762, https://doi.org/10.1111/j.1365-3040.1991.tb01440.x.

Thornley, J.H.M. 2002. Instantaneous canopy photosynthesis: Analytical expressions for sun and shade leaves based on exponential light decay down the canopy and an acclimated non-rectangular hyperbola for leaf photosynthesis. Ann. Bot. 89:451-458, https://doi.org/10.1093/aob/ mcf071.

von Caemmerer, S. 2000. Biochemical models of leaf photosynthesis. CSIRO Publishing, Clayton VIC, Australia. https://doi.org/10.1071/9780643 103405.

von Elsner, B., D. Briassoulis, D. Waaijenberg, A. Mistriotis, C. von Zabeltitz, J. Gratraud, G. Russo, and R. Suay-Cortes. 2000. Review of structural and functional characteristics of greenhouses in European Union countries: Part I, design requirements. J. Agr. Eng. Res. 75: 1-16, https://doi.org/10.1006/jaer.1999.0502.

Wang, W.M., Z.L. Li, and H.B. Su. 2007. Comparison of leaf angle distribution functions: Effects on extinction coefficient and fraction of sunlit foliage. Agr. For. Meteorol. 143:106-122, https://doi.org/10.1016/j.agrformet.2006.12.003.

Wise, R.R., A.J. Olson, S.M. Schrader, and T.D. Sharkey. 2004. Electron transport is the functional limitation of photosynthesis in field-grown Pima cotton plants at high temperature. Plant Cell Environ. 27:717-724, https://doi.org/10.1111/ j.1365-3040.2004.01171.x. 